\title{
Cournot Competition Between Teams: An Experimental StudY*
}

\author{
Philippe Raab \\ Department of Economics \\ University of Bonn
}

\author{
Burkhard C. Schipper ${ }^{\dagger}$ \\ Department of Economics \\ University of California, Davis
}

February 15, 2007

\begin{abstract}
In the economic literature on market competition, firms are often modelled as individual decision makers and the internal organization of the firm is neglected (unitary player assumption). However, as the literature on strategic delegation suggests, one can not generally expect that the behavior of teams is equivalent to the behavior of individuals in Cournot competition. Nevertheless, there are models of team-organization such that team-firms and individual firms are behaviorally equivalent. This provides a theoretical foundation for the unitary player assumption in Cournot competition. We show that this assumption is robust in experiments, which is in contrast to experimental results on price competition.
\end{abstract}

Keywords: Unitary player assumption, Group behavior, Experiments, Theory of the firm.

JEL-Classifications: C72, C91, C92, D21, D23, D43, L13, L22, M52.

*We like to thank two referees, David Budescu, Martin Dufwenberg, Uri Gneezy, Dan Kovenock, Rosemarie Nagel, Axel Ockenfels, Jörg Oechssler, and participants at ESA Meetings in Erfurt and Tucson for very helpful comments. Financial support by the Bonn Graduate School of Economics and the DFG through SFB/TR 15 is gratefully acknowledged.

${ }^{\dagger}$ Corresponding author: Department of Economics, University of California, Davis, One Shields Avenue, Davis, CA 95616, USA, Phone: +1-530-752 6142, Fax: +1-530-752 9382, Email:

bcschipper@ucdavis.com 


\section{Introduction}

\subsection{The Unitary Player Assumption in Cournot Oligopoly}

In the economic literature on market competition such as Bertrand or Cournot competition, firms are modelled as individual decision makers and the internal organization of the firm is neglected. This is known as the unitary player assumption. In contrast, studies of the theory of the firm (e.g. Hart, 1995) and personnel economics (e.g. Lazear, 1995, Prendergast, 1999) focus extensively on the internal organization of the firm but the market environment is considered just in a very stylized form. In quantity competition a là Cournot, teams may not display the same behavior as individuals. This is illustrated by the literature on strategic delegation in Cournot oligopoly, where the delegation of a principal to a manager leads to revenue maximization of the firm rather than to profit maximization (see Vickers, 1985, Fershtman and Judd, 1987). This example shows that the theoretical behavior of the firm depends crucially on the model of interaction within the team/firm. Thus from a theoretical point of view, the unitary player assumption in Cournot competition must be questioned. Is there any organizational form of the firm in a Cournot oligopoly, which generates behavior that is equivalent to the behavior of an individual decision maker? Fortunately, as we show in Section 2, this question can be answered in the affirmative. There do exist models of firm organizations in Cournot oligopoly generating behavior that is equivalent to an individual decision maker. This provides a theoretical foundation of the unitary player assumption in the Cournot oligopoly. For example, we consider a Cournot oligopoly where members of each firm choose efforts. For simplicity, the efforts of the members in each firm are aggregated additively to the quantity of the firm. We consider two different regimes of distributing the firm's profits among its members. First, profits may be distributed equally per head, an arrangement that may correspond loosely to a co-operative like an Israeli Kibbutz or a German Genossenschaft. Second, profits may be distributed proportionally according to each member's costly effort. We show that in both cases the Nash equilibrium quantities 
of the firms are equivalent to the Nash equilibrium in an analogous Cournot oligopoly in which each firm is an individual decision maker. The question is whether there is also empirical evidence for the behavioral equivalence of the two models of team-firms and the Cournot oligopoly with individual firms. We study experimentally this behavioral equivalence and find support for the unitary player assumption in Cournot competition.

\subsection{Related Literature}

Our findings are in direct contrast to recent analogous experimental results on price competition between teams. Bornstein, Kugler, Budescu and Selten (2006) building on previous work by Bornstein and Gneezy (2002) test for the unitary player assumption in Bertrand duopoly. In this study, the organizations of the firms are analogous to ours. However, instead aggregating the efforts to quantities, individual prices are aggregated additively to the firm's price. In their setting the equilibrium predictions are identical for both individual firms and team-firms. Yet, in their experiment they clearly reject the unitary player assumption as teams are more competitive than individual firms. We provide a discussion of what we believe drives the differences in Section 4.

An early experimental study investigating quantity competition between firms consisting each of a group of subjects is Sauermann and Selten (1959), who consider an asymmetric 3-firm Cournot oligopoly, in which each firm is represented by five subjects

on average. Those subjects play different roles: some communicate with the "market central office", others keep the books of the firm, etc. It is a dynamic problem because firms can borrow money for production and have to pay interest. Subjects play it over 30 periods. During the play, firms can acquire information about other firm's market share, debt etc. Sauermann and Selten (1959) report results that are remarkably close to one of the asymmetric Cournot Nash equilibria of the stage game under complete information. The aim of their study was not so much on testing Cournot's theory but on replicating a "realistic" yet controlled decision environment in order discover how subjects make decisions. In contrast, we aim to conduct a less complex experiment. Consequently we have 
more experimental control over the internal organization of the firm, i.e., the aggregation of decisions and the distribution of profits. Huck, Müller and Normann (2004) conduct an experiment to test strategic delegation a là Vickers (1985) and Fershtman and Judd (1987) in Cournot oligopoly. Theory predicts that firms set output levels well above the Cournot Nash equilibrium in order to maximize revenues instead profits. Yet, they find output levels similar to the Cournot Nash equilibrium. Together with our experimental findings we conclude that the Cournot outcome appears to be quite robust for firms that are represented by teams and engage in quantity competition no matter whether or not the Cournot outcome is the equilibrium prediction for such structure.

Nabantian and Schotter (1997) examine the influence of different incentive schemes on the production in teams. Among the incentive schemes they consider are also those analyzed in our study, namely the distribution of profits per head and the proportional distribution. They also aggregate decisions of subjects inside the firm additively, which is followed in our study as well. However, their work is restricted to an individual firm production problem. This leaves out completely strategic reasons for differences between behavior of teams and individuals. A firm's behavior is not just influenced by its internal organization but also by the opponents' reaction to the firm's internal organization. Our experiment allows to test for such strategic sources of potential violations of the unitary player assumption (see Observations 3 and 4).

Experiments on group versus individual behavior are an active and growing field of research. Bornstein (2007) provides a recent systematic survey and points out gaps in the literature. Most of the studies in the literature show that some relevant aspects of team behavior may be different from behavior of individuals. In contrast, we show with our study that there are decision making situations where the average behavior of groups and the average behavior of individuals are not significantly different. It is a worthy task for this field of research to identify classes of decision making situations and aspects of behavior in which groups (do not) differ from individuals, and if possible explain why such differences (do not) occur. To this extend, it may be helpful to consider in more theoretical detail the internal structure of teams and its effect on the interaction between 
teams. A useful classification of different types of teams is provided by Bornstein (2007). He distinguishes between unitary teams on one hand - i.e. a team who can reach a binding agreement on a joint strategy - and non-cooperative teams - i.e. a team whose members act independently without binding agreements. In this article, we are only concerned with the latter kind of teams.

The article is organized as follows: Section 2 introduces the experimental design and procedures. The experimental results are described in Section 3. We conclude with a discussion in Section 4. A translation of the instructions to the subjects is included in the Appendix.

\section{Design}

\section{$2.1 \quad$ Treatments}

Our model of market competition is a symmetric 3-firm Cournot oligopoly in which every firm faces the linear inverse demand function

$$
p(Q)=\max \left\{500-\frac{1}{6} Q ; 0\right\}
$$

where $Q=\sum_{j=1}^{3} q_{j}$ is the sum of all firms' quantities $q_{j} \in \mathbb{R}, j=1, \ldots, 3$. Each firm has unit marginal costs, i.e. $c\left(q_{j}\right)=q_{j}$ for all $q_{j} \in \mathbb{R}$. The profit function of firm $j=1,2,3$ is given by

$$
\pi_{j}\left(q_{j}, q_{-j}\right)=(p(Q)-1) q_{j}
$$

where $q_{-j}=\sum_{h \neq j} q_{h}$ denotes the sum of quantities of firm $j$ 's opponents.

Let $F_{j}$ be the set of members of firm $j$. Each firm $j=1,2,3$ is viewed as a team of members $i_{j} \in F_{j}$. Member $i_{j}$ of firm $j$ chooses the effort level $e_{i_{j}} \in \mathbb{R}$. For all treatments, $q_{j}=\sum_{i_{j} \in F_{j}} e_{i_{j}}$. That is, the quantity of each firm is the sum of its members' efforts.

We chose a 3-firm oligopoly rather than a duopoly because collusion occurs sometimes in duopolies but rarely in oligopolies with more than two firms (see Huck, Normann and 
Oechssler, 2004, and the discussion in Section 4). On the other hand, an oligopoly with more than 3 firms would require a larger number of subjects.

The four treatments outlined below differ in their models of the internal organization of the firm. In particular the incentive structure varies across treatments. However, the parameters are chosen such that there is a behavioral equivalence between firms and individual decision makers in theory (see Table 1).

\section{Treatment $C$}

Treatment $\mathrm{C}$ is a (C)ontrol-treatment with a standard 3-firm symmetric Cournot oligopoly. Each firm corresponds to an individual member (i.e., a unitary player) such that each individual's effort corresponds to a firm's quantity. The payoff function of each individual is simply the profit function of her firm (equation (2)).

\section{Treatment $S P$}

Treatment SP is a treatment with (S)ymmetric firm-size and (P)roportional incentives. Each firm has three members, i.e., $F_{j}=\left\{1_{j}, 2_{j}, 3_{j}\right\}$, for all firms $j=1,2,3$. Every

member faces identical linear costs of efforts $k\left(e_{i_{j}}\right)=83 \frac{1}{6} e_{i_{j}}$, that are chosen such as to yield a behavioral equivalence between individuals in treatment $\mathrm{C}$ and teams in this treatment in equilibrium (see Table 1). Moreover, every member is entitled to a share of his firm's profit that is proportional to his effort level. That is, the payoff function of each member $i_{j}=1_{j}, 2_{j}, 3_{j}$ is

$$
\pi_{i_{j}}\left(e_{i_{j}}, e_{-i_{j}}, q_{-j}\right)=\frac{e_{i_{j}}}{q_{j}} \pi_{j}\left(q_{j}, q_{-j}\right)-83 \frac{1}{6} e_{i_{j}},
$$

where $e_{-i_{j}}=\sum_{h \neq i} e_{h_{j}}$ is the sum of the other members' efforts in the same firm $j$.

Note that treatment SP is equivalent to a standard nine-firm Cournot oligopoly with marginal cost $k+c$. Thus, the treatment allows us also to check whether the framing of three players lead to deviations from the Cournot Nash equilibrium.

At the first glance, the treatment appears to be contrived by the additional effort 
costs $k$ for each member of a firm. Doesn't it add extraneous structure to the original Cournot oligopoly? Yes, it does add structure, which is usually neglected in the standard models. The effect of such internal structure is what we want to study here. If such effort cost wouldn't be added in this treatment, then a difference between observed behavior in treatments SP and C wouldn't be surprising and predicted by Nash equilibrium. The next two treatments do not require extra effort costs of the members but the profits of each firm are not allocated proportionally across members.

\section{Treatment SH}

Treatment $\mathrm{SH}$ is a treatment with (S)ymmetric firm-size and an equal allocation of a firm's profits per $(\mathrm{H})$ ead. The treatment is analogous to treatment SP except for the distribution of firm-profits and the effort costs. Effort costs $k\left(e_{i_{j}}\right)=0$ are nil so as to obtain a theoretical behavioral equivalence between individual firms and team firms (see Table 1). For each firm $j=1,2,3$, the payoff function of each member $i_{j}=1_{j}, 2_{j}, 3_{j}$ is

$$
\pi_{i_{j}}\left(q_{j}, q_{-j}\right)=\frac{1}{\sharp F_{j}} \pi_{j}\left(q_{j}, q_{-j}\right)=\frac{1}{3} \pi_{j}\left(q_{j}, q_{-j}\right) .
$$

That is, profits of the firm are allocated equally across members of the firm and this allocation is independent of any member's effort.

Note that in this treatment (as well as in treatment $\mathrm{AH}$ below) any distribution of efforts among members adding up to the Cournot Nash equilibrium quantity of the firm is a Nash equilibrium. Thus this treatment allows us to investigate the impact of an intra-firm coordination problem on the quantity of the firm and the market outcome. In comparison with treatment SP, we can evaluate the effect of two different rules of profit distribution among members of a firm. Again, we have in this treatment a theoretical behavioral equivalence between individual firms and team-firms (see Table 1).

\section{Treatment $A H$}

Treatment $\mathrm{AH}$ is a treatment with (A)symmetric firm-size and an equal allocation of profits per $(\mathrm{H})$ ead. The treatment is analogous to treatment $\mathrm{SH}$ except for the different 
sizes of the firms. Firm 1 consists just of a individual member, whose effort corresponds to the quantity of firm 1 . Firm 2 and 3 have three members each as in treatment SH before. Consequently, the payoff functions of each member differ depending on whether the member is in firm 1 or in the two other firms.

$$
\begin{gathered}
\pi_{1_{1}}\left(q_{1}, q_{-1}\right)=\frac{1}{1} \pi_{1}\left(q_{1}, q_{-1}\right)=\pi_{1}\left(q_{1}, q_{-1}\right), \\
\pi_{i_{j}}\left(q_{j}, q_{-j}\right)=\frac{1}{3} \pi_{j}\left(q_{j}, q_{-j}\right), j=2,3 .
\end{gathered}
$$

This treatment with asymmetric team-size allows us to study the effect of different teamsizes on the competition within markets. Together with the treatment SH, treatment $\mathrm{AH}$ enables us to analyze first, whether individuals behave differently towards teamfirms than towards other individual firms, second, whether team-firms behave differently in markets with individual firms than in markets with other team firms only, and third, whether the number of members per firm has any influence on results.

Table 1 provides an overview of prominent outcomes such as the unique (symmetric) Nash equilibrium, the collusive outcome and the competitive outcome ${ }^{1}$, revealing the theoretical behavioral equivalence between those treatments. The calculations are standard and thus omitted. Note again, that in treatments $\mathrm{SH}$ and $\mathrm{AH}$ there is a continuum of Nash equilibrium efforts since every distribution of efforts over members of a firm that sums up to the Nash equilibrium quantity of the firm is a Nash equilibrium effort level. Thus players face a co-ordination problem within each firm with more than one player. The table reports just the symmetric Nash equilibrium effort level. Note further, that due to the individual effort costs in treatment SP, the collusive and the competitive level from the individual's view differs from those corresponding levels from the firm's view. Thus the theoretical behavioral equivalence between treatments $\mathrm{SP}$ and $\mathrm{C}$ is restricted to the Cournot Nash equilibrium.

\footnotetext{
${ }^{1}$ In the competitive outcome, the firm does not perceive any influence on the price.
} 
Table 1: Behavioral equivalence across treatments

\begin{tabular}{|c|c|c|c|c|}
\hline & \multicolumn{4}{|c|}{ Treatments } \\
\hline Outcomes & SP & SH & AH & C \\
\hline Nash equilibrium & & & & \\
Individual effort & 249.5 & $249.5^{a}$ & $249.5^{a, b} / 748.5^{c}$ & 748.5 \\
Firm's quantity & 748.5 & 748.5 & 748.5 & 748.5 \\
Market quantity & 2245.5 & 2245.5 & 2245.5 & 2245.5 \\
\hline Collusive outcome & & & & \\
Individual effort & $166 \frac{1}{3} / 138.61^{d}$ & $166 \frac{1}{3}^{a}$ & $166 \frac{1}{3}^{a, b} / 499^{c}$ & 499 \\
Firm's quantity & $499 / 415.83^{d}$ & 499 & 499 & 499 \\
Market quantity & $1497 / 1247.5^{d}$ & 1497 & 1497 & 1497 \\
\hline Competitive outcome & & & & \\
Individual effort & $332 \frac{2}{3} / 277.22^{d}$ & $332^{a}$ & $332^{a}$ & \\
Firm's quantity & $998 / 831.67^{d}$ & 998 & 998 & 998 \\
Market quantity & $2994 / 2495^{d}$ & 2994 & 2994 & 2994 \\
\hline
\end{tabular}

${ }^{a}$ symmetric outcome

${ }^{b}$ effort of a member in three-member firm

${ }^{c}$ effort of a member in the individual-member firm

${ }^{d}$ from the individual's point of view

\subsection{Experimental Procedure}

Motivated by previous Cournot experiments in the literature (e.g. Huck, Normann and Oechssler, 1999), the game in each of our treatments was played repeatedly for 40 rounds with fixed matching. We chose fixed matching over random matching because first, we wanted to enable subjects to learn, and second, the lab had just 18 terminals available so that effect of "reshuffling" each of the 9 subjects in a market is limited. It is also known that collusion occurs rarely in Cournot tripolies even with fixed matching (see Huck, Normann and Oechssler, 2004). We chose 40 rounds mainly because on one hand, experiments on Cournot oligopoly in the literature (e.g. Huck, Normann and Oechssler, 1999) find 40 rounds sufficient for learning. On the other hand, we did not want to extent 
the duration of the experiment to more than $2 \frac{1}{2}$ hours.

Each subject had to choose her effort level from the grid $\{0,0.1,0.2, \ldots, x\}$, whereby $x$ was fixed at 1500 in treatment SP, SH and $\mathrm{AH}$ (for subjects in three-member firms) and at 4500 in treatment $\mathrm{C}$ and $\mathrm{AH}$ (for subjects in individual member firms). The grid was chosen such to make all prominent outcomes feasible and allow also for the monopoly outcome in every treatment.

Each session consisted of three stages: the briefing stage, the interaction-stage, and the debriefing stage. Stages 2 and 3 were computerized in the experimental software z-Tree (Fischbacher, 1999).

In the briefing stage, subjects received written instructions that were read aloud by the experimenter. In the appendix, we include as an example an English translation of the German instructions for treatment SP, which we consider the most complex instruction among all treatments. The instructions describe the game as well as the details of the session. The game was indeed framed as competition among firms as presented in this article. The demand function, costs functions, effort costs, the profit-distribution and team-sizes were public knowledge.

The appendix provides an example of a screen-shot. Such an example was also presented and explained to subjects in the instructions. Subjects were encouraged to ask questions about the instructions, which some did. Answers were given publicly. After the instructions, an example was computed in front of the subjects by the experimenter to enhance the subjects' understanding of the incentives. After that, each subject had to take a simple test that required the calculation of firm-profits and member-payoffs. ${ }^{2}$ Subjects had a standard calculator available. Only after all subjects successfully completed the test, the interaction stage was started.

In the interaction stage, subjects had to play the game repeatedly for 40 rounds. Since the aim of our experiment was not to analyze the impact of limited computational

\footnotetext{
${ }^{2}$ The values in the examples did not correspond to any prominent value in the game. There was also no evidence that in the experiment subjects started out with the values of the examples.
} 
capabilities on outcomes, we provided the subjects with three different "trial"-calculators (see the screen-shot in the appendix). Similar calculators have been employed in previous experiments on Cournot oligopoly (see for instance Huck, Normann and Oechssler, 1999). It was understood from the instructions that the inputs in those calculators have no influence on their payoffs from the experiment. First, there was a calculator (2a) that automatically computed the member's payoff if she inserted a number each for her own effort, the total effort by other members of the team and the total quantity of opponent-firms (the "trial calculator"). ${ }^{3}$ Second, there was a calculator (2b) that automatically computed the member's best response and profit if she inserted a number each for the total effort by other members of the team and the total quantity of opponent firms (the "best-reply calculator"). Subjects could try out as much as they wanted and the computed payoffs were listed below the calculators respectively. Those lists were automatically deleted after each round. However, all entries to the calculators have been recorded by the experimenter automatically. Third, there was a standard calculator on the computer available. After all subjects in the session had chosen and confirmed their effort levels, payoffs were computed automatically and the next round was started.

All subjects knew what feedback they would receive after each round. Between the rounds, each subject received feedback information on her own effort, the total effort of all other members in her firm (only in treatment SP, SH, and for team-firms in treatment $\mathrm{AH}$ ), and the total quantity of all other firms in the previous period. Each subject also received feedback information about her own profit but not about profits of other teammembers or other firms. This information is for instance sufficient for myopic best-reply learning. ${ }^{4}$

\footnotetext{
${ }^{3}$ The input fields of the calculator was adjusted to the different treatments.

${ }^{4}$ One can show that the game in each treatment has a potential function. To see this, note that according to Monderer and Shapley (1996) a Cournot oligopoly with linear demand and costs has a potential function. Notice that treatment SP is equivalent to a 9-firm Cournot oligopoly with linear costs $c+k$. Finally, note that each of the treatments $\mathrm{SH}$ and $\mathrm{AH}$ is equivalent to a 3-person Cournot game except for the a fixed factor $\sharp F_{j}^{-1}$ in firm $j$ 's profit function. Yet this factor still allows for the
} 
The debriefing stage consisted of a computerized questionnaire that asked for the following information: the major of studies, the term of studies, the gender, whether the subject participated previously in a lecture on game theory or not, and how the participant would summarize his/her behavior. At the end of the questionnaire the final payoff converted in EURO was announced to the subject. The exchange rate from the experimental currency Taler to EURO was announced in the instructions. It varied between 2500 to 400 Taler per Euro-cent depending on the treatment and the type of firm such as to equalize the levels of incentives between subjects in individual firms and subjects in team-firms. If all treatments were conducted with the same exchange rate for every subject, then any differences could be due to the different level of incentives rather than to "team" effects. The final payoffs were paid out to the subjects immediately after the session concluded.

Finally, we need to mention that losses were possible. Thus subjects could possibly become bankrupt even with the initial lump sum payment that subjects received upfront. Indeed, this occurred in a few cases in the early rounds of the experiment in the treatment SP. In such cases we bilaterally agreed with those subjects on a loan such that they could continue with the experiment.

\section{Results}

The experiment was conducted in the Bonn Laboratory of Experimental Economics in May 2003. For each treatment, we generated 6 independent observations. (Each market is one independent observation.) In total 168 subjects participated in our experiment. According to answers to the questionnaires at the end of each session, about $58 \%$ of the subjects majored in economics, $23 \%$ in law, $5 \%$ in languages and the rest in history, communication, political science etc. About $62 \%$ of the subjects were undergraduates (3

existence of an ordinal potential. The existence of a potential in each treatment implies that sequential myopic best-reply converges to the Nash equilibrium in finite time (see Monderer and Shapley, 1996) in any of our treatments. 
years maximum). $16 \%$ of the subjects where above the 8 th semester. The sex ratio was almost balanced with about $49 \%$ female subjects. About $19 \%$ of the subjects announced that they had previously discussed game theory in a course.

Each session took about 2 to $2 \frac{1}{2}$ hours including briefing and debriefing. The payoff to each student was about 18 Euros on average.

\subsection{Market Quantities}

Figure 1 presents the average market quantities per treatment for the 40 periods. A first glance suggests that average market quantities are very similar across treatments. Average market quantities are slightly larger in treatments SH and AH. Figure 1 also reveals that market quantities are distributed closely around the Cournot Nash equilibrium.

Figure 1: Average market quantities

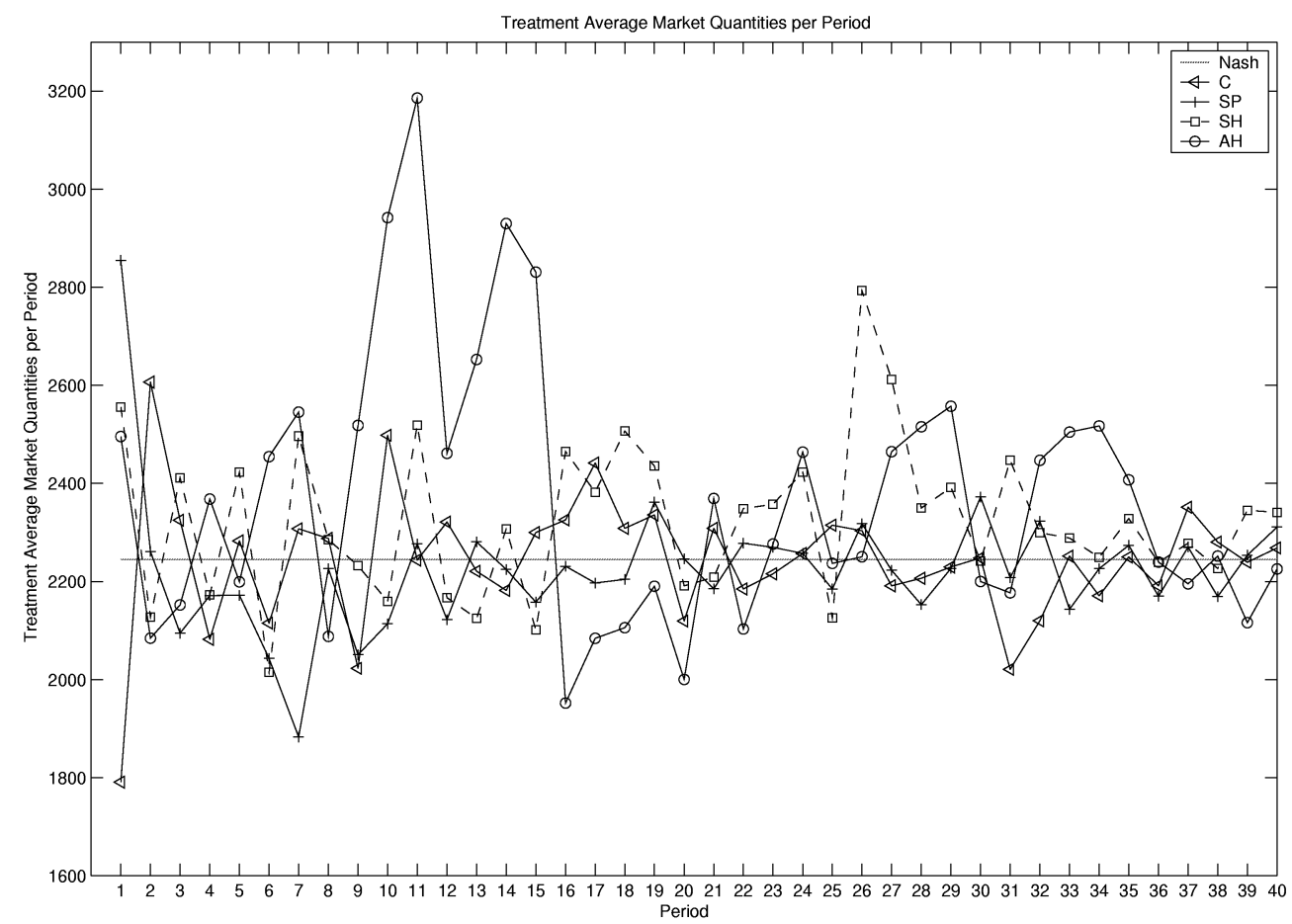

Table 2 provides the summary statistic for market quantities per treatment. Treat- 
Table 2: Summary statistic of market quantities across treatments

\begin{tabular}{|l|c|c|c|c|}
\hline & \multicolumn{4}{|c|}{ Treatments } \\
\hline & SP & SH & AH & C \\
\hline Average & 2224.74 & 2324.37 & 2369.05 & 2243.06 \\
Standard deviation & 292.24 & 396.80 & 510.10 & 306.34 \\
St. dev. to Nash equilibrium & 290.94 & 427.96 & 522.80 & 306.46 \\
St. dev. to competitive outp. & $825.50 / 397.94^{a}$ & 782.11 & 843.19 & 813.40 \\
St. dev. to collusion & $789.62 / 1024.20^{a}$ & 918.57 & 1020.00 & 813.29 \\
\hline
\end{tabular}

${ }^{a}$ from the individual's view

ments SH and AH have slightly higher average market quantities than treatments SP and C. The latter two have also smaller standard errors. The Cournot Nash equilibrium is in all treatments the best predictor compared to the competitive outcome or the collusive outcome. However, treatments SP and C deviate less from the Cournot Nash equilibrium prediction than treatments $\mathrm{SH}$ and $\mathrm{AH}$.

Figure 2 displays the market quantities for each of the six markets per treatment for the 40 periods of the experiments. Again, there are no substantial differences between and within the treatments. The market quantities are distributed around the Cournot Nash equilibrium.

We can not reject the hypothesis that average market quantities in treatment SP are not different from treatment $\mathrm{C}$ even at the 0.29 significance level with a two-sided Wilcoxon-Mann-Whitney test and at the 0.1 level with a Robust Rank Order test. ${ }^{5}$ The same holds for treatment $\mathrm{SH}$ versus treatment $\mathrm{C}$. For treatment $\mathrm{AH}$, we can not reject the hypothesis that average market quantities are not different from treatment $\mathrm{C}$ at the 0.045 significance level with a two-sided Wilcoxon-Mann-Whitney test and at the 0.05 level with a Robust Rank Order test. The lower significance levels for treatment AH are

\footnotetext{
${ }^{5}$ See Siegel and Castellan, 1988, for explanations of all the tests used in this article. Note that 0.1 is the highest significance level in Siegel and Castellan (1988) for the Robust Rank Order test.
} 
Figure 2: Market quantities per treatment
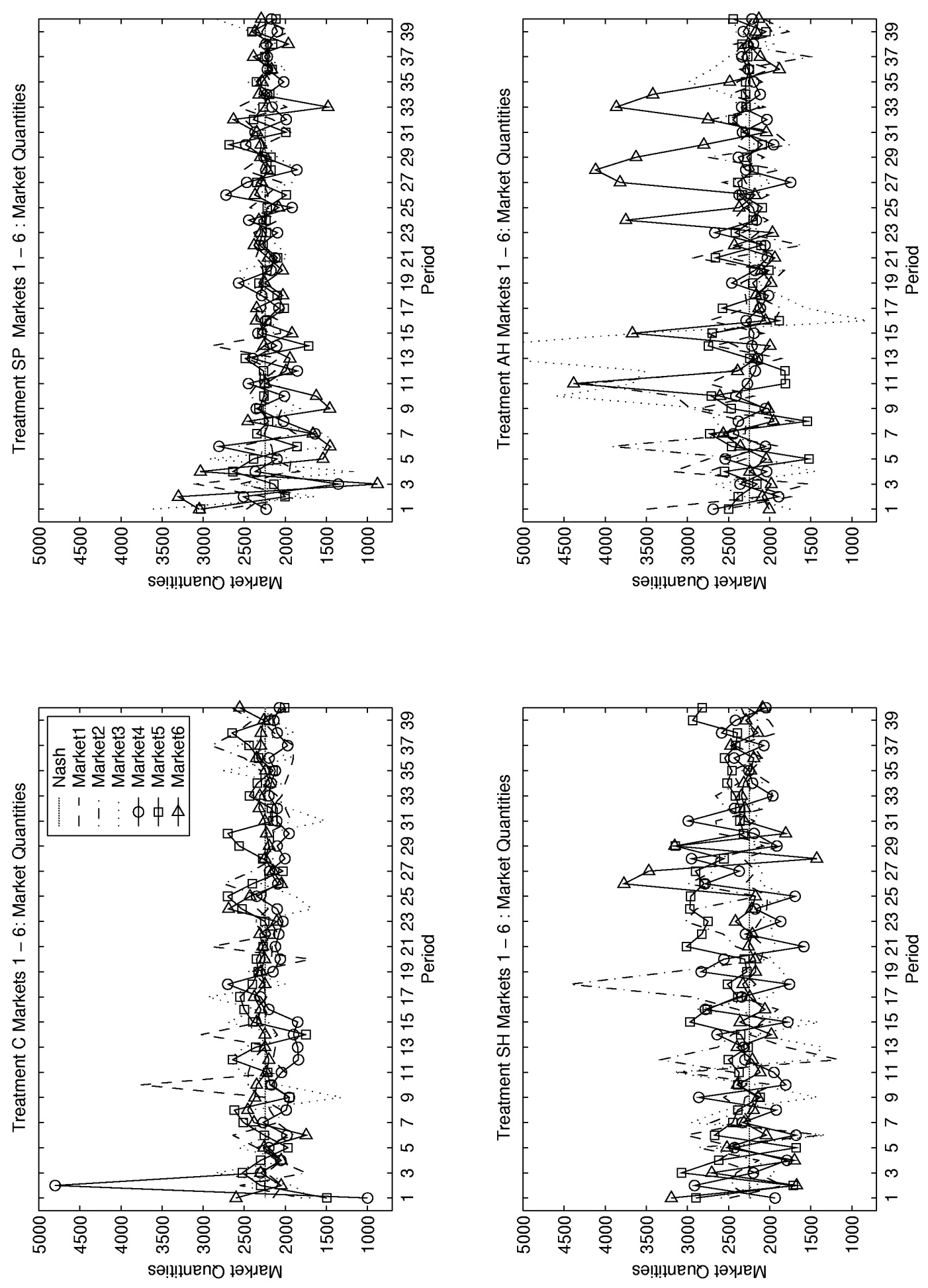
probably due to two extreme outliers ${ }^{6}$ in treatment AH. If we omit these two observations and compare the 4 remaining average market quantities of $\mathrm{AH}$ with the ones of $\mathrm{C}$ we cannot reject a behavioral equivalence at the 0.1 significance level.

Observation 1 Average market outputs do not differ significantly across treatments $C$, $S P$, and SH. For treatment AH significance levels are lower than in treatment SP and $S H$.

We can not reject the hypothesis that average market quantities in any of the treatments are not different from the Cournot Nash equilibrium prediction even at the 0.2 significance level (two sided Kolmogorov-Smirnov One Sample test).

Observation 2 Average market outputs do not differ significantly from the total Cournot Nash equilibrium market output.

According to Table 2, standard deviations are higher in treatments $\mathrm{SH}$ and $\mathrm{AH}$ than in treatments SP and C. Indeed, judging by the Figures 1 and 2, the volatility seems to be higher in treatments $\mathrm{SH}$ and $\mathrm{AH}$ than in $\mathrm{SP}$ and $\mathrm{C}$. This is probably due to the co-ordination problem subjects faced within each firm in those treatments. Recall that any distribution of efforts among members of a firm that adds up to the Cournot Nash equilibrium quantity of the firm is a Nash equilibrium effort. This multiplicity of Nash equilibrium effort levels presents a coordination problem. Figure 2 may also suggest that the volatility does not decrease and perhaps even increases in treatment $\mathrm{SH}$ and $\mathrm{AH}$. Could the coordination problem become more severe over time? In treatments $\mathrm{SH}, \mathrm{AH}$, and $\mathrm{C}$ there is only one market each where the standard deviation is higher in the last 20 periods than in the first 20 periods. In treatments SP there is no market with an increased standard deviation in the last 20 periods.

\footnotetext{
${ }^{6} \mathrm{An}$ observation is here defined to be an extreme outlier if the market quantity was above 4000 more than once in the last 35 periods of the play. At such output levels every player is certain to make large losses.
} 
Table 3: Average quantities of team-firms and individual firms

\begin{tabular}{|l|c|c|c|}
\hline & \multicolumn{3}{|c|}{ Treatments } \\
\hline & SH & AH & C \\
\hline team firms & 787.42 & 813.13 & n.a. \\
individual firms & n.a. & 742.78 & 747.69 \\
\hline
\end{tabular}

\subsection{Strategic Behavior towards Teams vs. Individual Players}

We want to test whether team-firms in markets with individual firms behave significantly different from team-firms in markets with other team-firms only. Our experimental design allows us to control for potential strategic sources of differences in behavior between team-firms and individual firms. The behavior of a firm may not just be influenced by the internal organization of the firm itself but also by the internal organization within an opponent firm. Notice that treatment $\mathrm{AH}$ is more similar to treatment $\mathrm{SH}$ than treatment SP or C. Hence we compare data from team-firms in treatment AH to teamfirms in treatment $\mathrm{SH}$ instead SP or C. In Table 3 we present the averages quantities of team-firms and individual firms for the relevant treatments. Since we have three (resp. two) team-firms per market in treatment $\mathrm{SH}$ (resp. AH), we randomly select one from each market in order to get six independent observations from each treatment. We can not reject the hypothesis that average quantities of team-firms in markets with an individual firm (treatment $\mathrm{AH}$ ) are not different from average quantities of team-firms in markets with other team-firms only (treatment $\mathrm{SH}$ ) at the 0.47 significance level using a two-sided Wilcoxon-Mann-Whitney test and at the 0.1 level using a Robust Rank-Order test.

Observation 3 Average quantities of team-firms in markets with an individual firm (treatment AH) are not significantly different from average quantities of team-firms in markets with other team-firms only (treatment SH). 
Similarly, we also want to test whether individual firms in markets with team-firms behave significantly different from individual firms in markets with other individual firms only. To test this, we consider data from individual firms in treatment $\mathrm{AH}$ and compare these to quantities of individual firms in treatment $\mathrm{C}$. Whereas in each market of the treatment $\mathrm{AH}$ we have an individual firm (playing with two other team-firms), in treatment $\mathrm{C}$ we have three individual firms in each market. For the test, we select randomly one of the three individual firms in each market in treatment $\mathrm{C}$. In this way we obtain six independent observations each for treatments $\mathrm{AH}$ and $\mathrm{C}$, which we test for significant differences. We can not reject the hypothesis that average quantities of individual firms in market with team-firms (treatment $\mathrm{AH}$ ) are not different to average quantities of individual-players in markets with other individual firms only (treatment C) at the 0.35 significance level using a two-sided Wilcoxon-Mann-Whitney Test and at the 0.1 level using a Robust Rank Order test.

Observation 4 Average quantities of individual firms in markets with team-firms (treatment AH) are not significantly different from average quantities of individual firms in markets with other individual firms only (treatment $C$ ).

\subsection{Internal Coordination Problem}

As pointed out in Section 2, subjects face a coordination problem in treatments $\mathrm{SH}$ and $\mathrm{AH}$, since any distribution of efforts among members of a firm that adds up to the Cournot Nash equilibrium quantity of the firm is a Nash equilibrium effort.

In treatments $\mathrm{SH}$ and $\mathrm{AH}$, the standard errors of the firm quantities and individual efforts are higher than in treatments SP and C (Table 4). This might be due to the coordination problem that subjects faced in treatments $\mathrm{SH}$ and $\mathrm{AH}$. However, in treatment AH the standard deviation of subjects in the three-player firms (191.08) is almost as high as the standard deviation of subjects in individual firms (204.13). This calls former explanation with the co-ordination problem into question since the individual firm does not face a co-ordination problem. We also observe that standard errors for team-firms 
Table 4: Standard errors of firm quantities and individual efforts

\begin{tabular}{|c|c|c|}
\hline Treatment & Individual effort & Firm's quantity \\
\hline SP & 79.44 & 149.35 \\
\hline SH & 121.67 & 201.27 \\
\hline AH & $191.08^{b}$ & $204.13^{a} / 264.72^{b}$ \\
\hline C & - & 162.37 \\
\hline
\end{tabular}

${ }^{a}$ only 1-player firms

${ }^{b}$ only 3 -player firms

in the treatment $\mathrm{AH}$ are higher than standard errors for team-firms in the treatment SH. The latter are at about the same magnitude as standard errors of individual firms in treatment $\mathrm{AH}$. It appears that the heterogeneity of the firm size in the treatment $\mathrm{AH}$ increases the standard error of quantities of team-firms.

Standard errors do not decrease during the 40 rounds for a substantial portion of subjects and firms. I.e., standard errors for the last 20 rounds are higher for a sizeable portion of individual firms and team-firms across treatments, especially in treatments $\mathrm{SH}$ and $\mathrm{AH}$ (about $30 \%$ of individual firms and about $20 \%$ of team firms). This suggests that the coordination problem is not resolved during the 40 rounds of play.

Our data on individual efforts/quantities suggest some behavioral heterogeneity among subjects. A way of capturing this heterogeneity is by categorizing different types of subjects. We distinguish between aggressive and defensive subjects and firms. We say a subject (resp. firm) is aggressive if $60 \%$ of the periods she (resp. it) plays at least 50 (resp. 100) grid-points above the Nash equilibrium level. Similarly, a subject (resp. firm) is defensive if $60 \%$ of the periods she (resp. it) plays at last 50 (resp. 100) gridpoints below the Nash equilibrium level. Table 5 reveals the distribution of types across treatments. For individual efforts, treatment $\mathrm{SH}$ and $\mathrm{AH}$ have a higher percentage of extreme types compared to SP. Note that in those treatments there were also asymmetric equilibria involving asymmetric levels of efforts across individuals within the same firm. Similarly, treatment SH has more extreme firms compared to SP, AH, and C. There is not 
Table 5: Types of players

\begin{tabular}{|c|c|c|c|c|}
\hline & SP & SH & AH & C \\
\hline Aggressive individual & $16.7 \%$ & $25.9 \%$ & $25.0 \%$ & - \\
\hline Defensive individual & $11.1 \%$ & $35.2 \%$ & $27.8 \%$ & - \\
\hline Aggressive firms & $5.6 \%$ & $11.1 \%$ & $2.8 \%^{a} / 0.0 \%^{b}$ & $5.6 \%$ \\
\hline Defensive Firms & $5.6 \%$ & $16.7 \%$ & $2.8 \%^{a} / 0.0 \%^{b}$ & $5.6 \%$ \\
\hline
\end{tabular}

${ }^{a}$ only in 3-player firms

${ }^{b}$ only in 1-player firms

much difference among the latter three treatments in terms of the distribution of types of firms. Remarkably, the percentage of defensive and aggressive types of firms is almost equal in each treatment. Note that in a strategic situation like the Cournot oligopoly, the number of aggressive and defensive firms may not be independent. It suggests tendencies towards Stackelberg outcomes.

Observation 5 Treatments $S H$ and AH lead to more asymmetry among individual effort levels as compared to treatment SP. This is in line with the existence of asymmetric Nash equilibrium efforts in treatments $\mathrm{SH}$ and $\mathrm{AH}$.

\subsection{Convergence and Learning}

All the results so far concern the average behavior in the experiment. We do not expect that subjects choose exact equilibrium efforts over all 40 periods. Rather, our design allows subjects to learn using for instance a myopic best-reply process.

To analyze our data, we say here that a time series of a variable converges to the Nash equilibrium level if in the last 20 rounds a higher percentage of cases is within a range of $+/-\delta$ around the Nash equilibrium level than in the first 20 rounds. We fix $\delta$ at 30, 80, and 100 grid-points for the individual efforts, the firm quantities and the market quantities respectively.

In Table 6 we report the percentage of cases which do belong to the interval in the 
Table 6: Percentage of cases within the interval around symmetric Nash equilibrium

\begin{tabular}{|c|c|c|c|}
\hline Treatment & Individual efforts & Firms' quantities & Market quantities \\
\hline SP & $29.8 \% / 36.8 \%$ & $39.2 \% / 52.5 \%$ & $31.7 \% / 54.2 \%$ \\
\hline SH & $13.9 \% / 15.0 \%$ & $26.7 \% / 42.5 \%$ & $23.3 \% / 27.5 \%$ \\
\hline AH & $12.9 \% / 11.7 \%^{a}$ & $31.9 \% / 45.6 \%$ & $20.0 \% / 34.2 \%$ \\
\hline C & - & $45.8 \% / 57.8 \%$ & $33.3 \% / 45.0 \%$ \\
\hline
\end{tabular}

${ }^{a}$ 3-player firm

first 20 rounds /last 20 rounds

first and second 20 periods of the experiment. In almost all treatments (except for the individual efforts in treatment $\mathrm{AH}$ ) a larger percentage of cases lies within the interval in the last 20 periods of the experiment compared to the first 20 periods. Whereas about $50 \%$ of firm quantities and market quantities lie in the interval for treatments SP and C, this is lower in treatments $\mathrm{SH}$ and $\mathrm{AH}$. Percentages for individual values are lower than for firm and market quantities which is probably due to an averaging effect.

We find only weak evidence for myopic best-reply learning across treatment. Figure 3 shows the mean square deviation between each subject's best-reply and the actual effort choice per period per treatment. Although the mean square deviation declines over 40 periods, it is still substantial at the end of the 40 rounds.

Observation 6 There is only weak evidence for myopic best-reply learning and convergence to Nash equilibrium levels.

\subsection{Calculator Data}

One feature of our experimental design is the collection of data calculated by subjects. We are interested how subjects solve this complex interactive decision problem. To analyze this question, we like to relate the inputs to the calculators to individual quantities. Do subjects choose an effort level that they calculated beforehand? Are subjects' "beliefs" about opponents correct in the sense that opponents behave as assumed in their previous 
Figure 3: Mean square deviation between best-reply and individual efforts

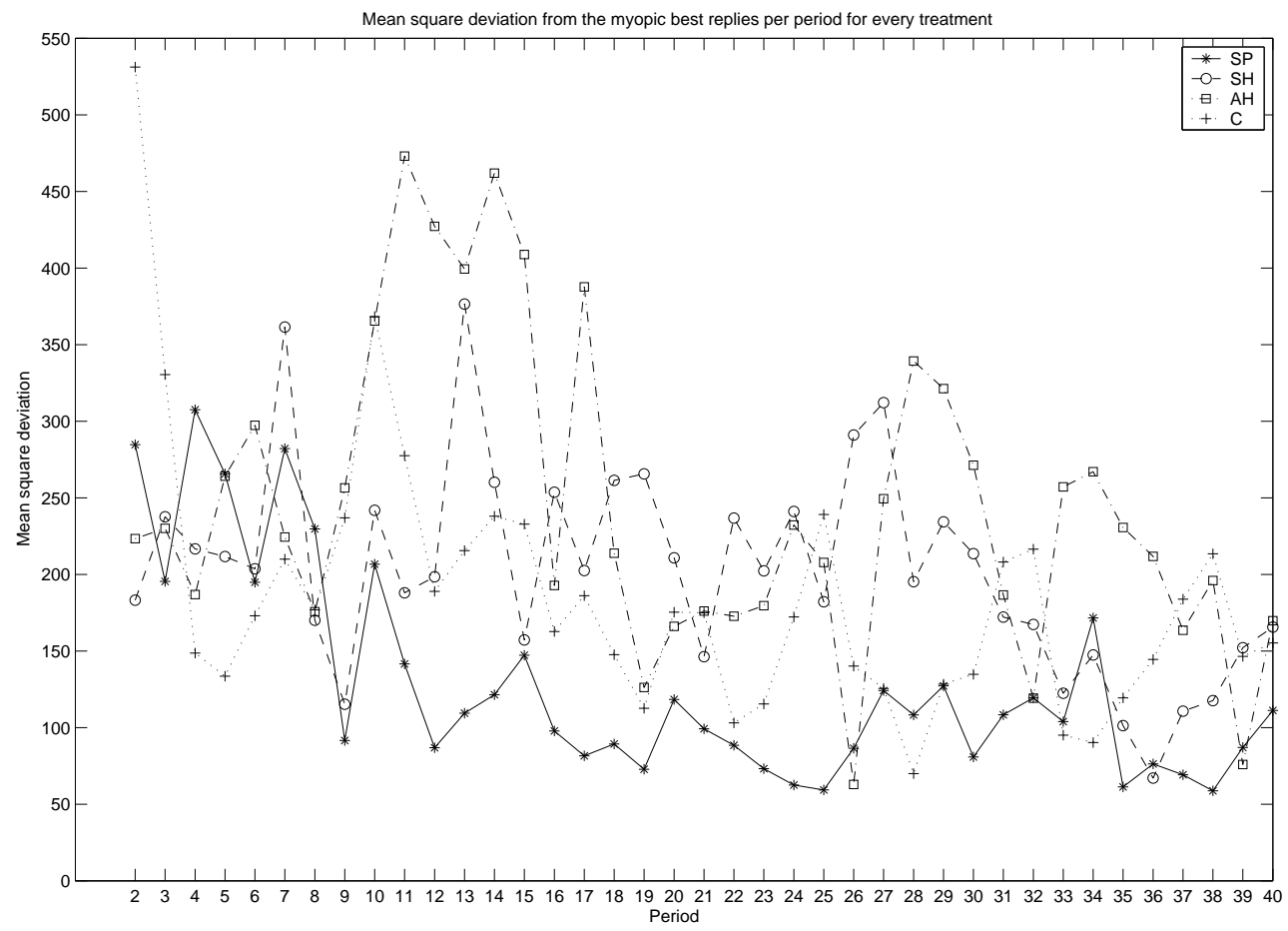

calculations? Do subjects search for best or better replies?

On average each subject made about 70 calculations with any of the two calculators (2a, $2 \mathrm{~b})$ during the experiment. This is about 1.75 calculations per head and per period. Thus subjects spent quite some efforts to solve the interactive decision problem. In about $38.3 \%$ of all calculations, subjects used the trail calculator, whereas $61.7 \%$ of the time the best-reply calculator was used. These proportions did not vary much across treatments. The best-reply calculator was used more often than the trial calculator in all treatments.

The four charts in Figure 4 provide information about the use of calculators. The upper left chart shows the average number of calculations per head over all 40 periods. It starts with 5 to 7 calculations per period and falls to 1 to 2 calculators per period after the tenth period. It appears that treatment $\mathrm{C}$ required less calculations than the other treatments. Probably subjects perceived treatment $\mathrm{C}$ less complex than others. The 
Figure 4: Calculator
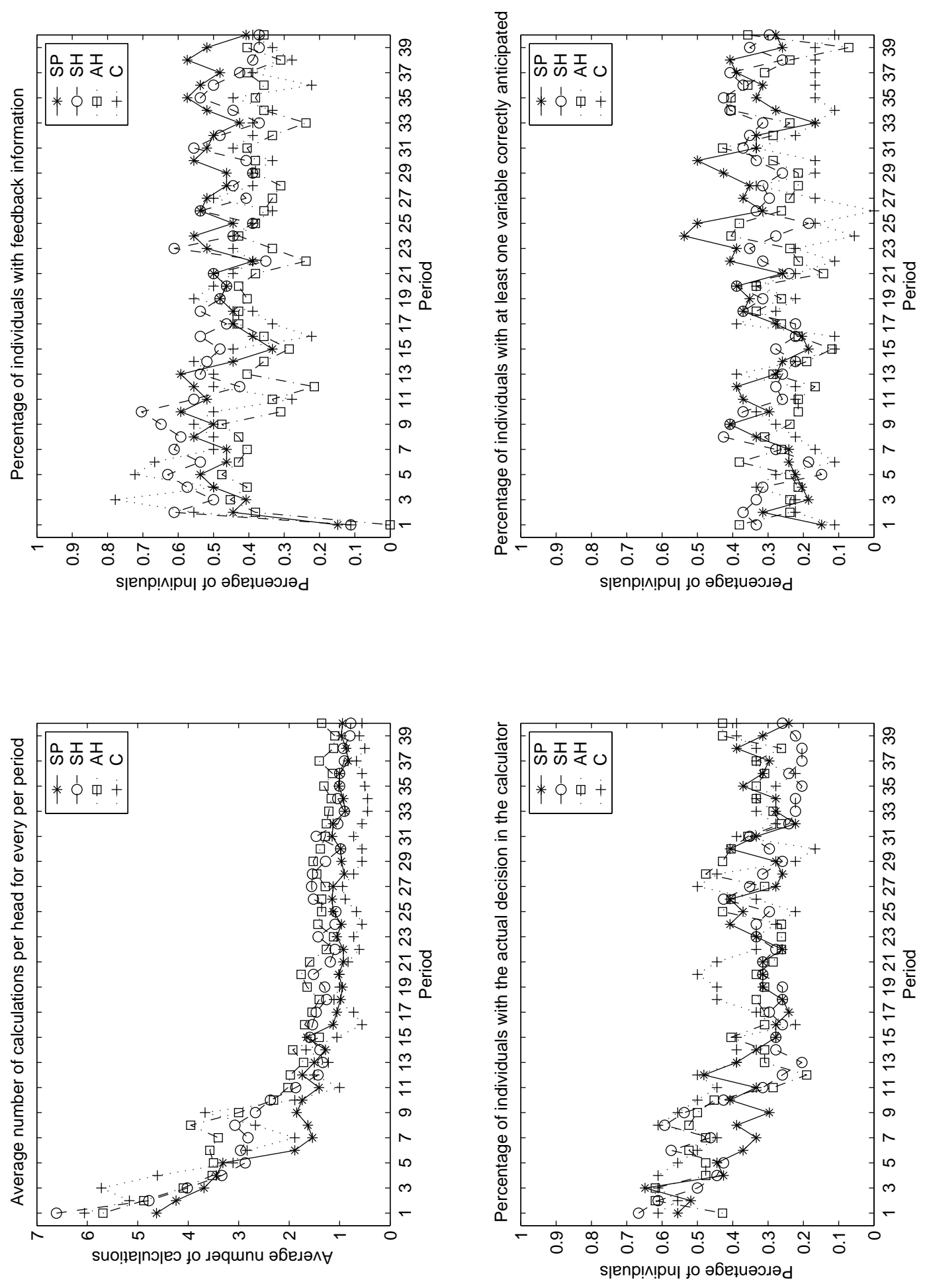
chart in the lower left corner answers the question about the percentage of individuals that played a decision previously calculated. It starts with $50 \%$ to $70 \%$ and seems to fall below 50\% (in treatment SH even to about 20\%). The upper right chart indicates that only about half of the subjects used their calculations for checking the result of the previous period. Thus it is unlikely that they consciously used some myopic bestresponse adjustment process. Finally, the lower right graph shows that only a small fraction of individuals used at least one variable that also appeared in the subsequent period. This fraction does not increase over the 40 periods. If we assume that subjects try out what they believe opponents will do, then the graph indicates that subjects were to a large extend unable to correctly anticipate the decisions of others and did not learn to anticipate other's decisions.

In the questionnaire at the end of the experiment, we asked subjects to describe briefly how they reached their decisions. From those descriptions, we got the impression that many participants use the calculators in their decision heuristics. They may not try out what they exactly going to play but may bound efforts levels/quantities above and below.

The time taken for decisions per period decreased from about 200 seconds at the beginning of the 40 rounds to about 50 seconds after the 10th round, and to about 30 seconds at the end. Almost across all periods these decision times were slightly higher in treatments $\mathrm{SH}$ and $\mathrm{AH}$ compared to treatments $\mathrm{SP}$ and $\mathrm{C}$.

\section{Discussion}

Our experimental results on the unitary player assumption in quantity competition a là Cournot are in stark contrast to results by Bornstein, Kugler, Budescu and Selten (2007), who reject the unitary player assumption in price competition a là Bertrand. What could account for the differences? There are two focal differences between the experiments: the incentive structure and the number of firms in the market. While one 
may expect the different incentive structure to be the most likely culprit, we actually believe it is mainly due to a number-effect. Formally, the Bertrand duopoly with individual firms in Bornstein, Kugler, Budescu and Selten (2007) is a two-player game whereas their Bertrand duopoly with team-firms are four or six-player games. There is quite some experimental evidence (Fouraker and Siegel, 1963, Chapter 10, Dolbear et al., 1968, and Dufwenberg and Gneezy, 2000) that Bertrand duopolies tend to collusion whereas Bertrand oligopolies with larger number of players are more competitive. This holds for fixed matching (Fouraker and Siegel, 1963, Dolbear et al., 1968) as well as random matching (Dufwenberg and Gneezy, 2000) between the rounds. Given the experimental evidence on the number effect in Bertrand oligopoly, it may be justified to ask whether the differences found by Bornstein, Kugler, Budescu and Selten (2007) between the individual setting and the team-player setting can be attributed to a number effect rather than a team effect. They find collusion in the individual Bertrand duopoly but more competitive prices in team-player Bertrand duopoly. Based on the findings in above mentioned experimental literature, we conjecture that in an experiment analogous to Bornstein, Kugler, Budescu, and Selten (2007) but with a sufficient large number of firms, one can not reject the unitary player assumption.

A caveat applies to the suggestion that the team effect found in Bertrand by Bornstein, Kugler, Budescu and Selten (2007) may be due to a number effect. Dufwenberg and Gneezy (2000, p. 20) sketch a theoretical argument for the number effect in Bertrand oligopoly based on players' expectations of opponents' mistakes, where a mistake is interpreted as a large deviation from the Nash equilibrium price. Players can benefit from mistakes of opponents which allows them to demand higher prices as well, but the larger the number of opponents the lower is the probability that all opponents make a mistake. Such argument does not extend to the team games studied by Bornstein, Kugler, Budescu and Selten (2007) like their "private profit" setting. The reason is that the marginal expected profit from a price increase may actually (weakly) decrease in the joint probability of mistakes by members of a player's own team, while the marginal expected profit from a price increase (weakly) increases in the joint probability of mistakes by opponents 
in a Bertrand oligopoly. So adding additional team-members to a player's team may be beneficiary to the player, while adding additional team-members to an opponent's team or additional firms hurts the player. Yet, this line of arguments suggest that eventually experiments on Bertrand oligopoly with asymmetric team-sizes (analogous to our treatment $\mathrm{AH}$ ) are required to disentangle fully the team effect from a number effect.

The arguments by Dufwenberg and Gneezy (2000) do not extend to Cournot oligopoly without further assumptions. While in Bertrand oligopoly studied by Dufwenberg and Gneezy (2000) or Bornstein, Kugler, Budescu and Selten (2007) mistakes can only involve higher prices than Nash equilibrium, mistakes in Cournot oligopoly can go in any direction. Since actions are aggregated within a team (and among opponents), mistakes may even offset each other. Nevertheless, a number effect has been also reported for experimental Cournot oligopolies. Huck, Normann and Oechssler (2004) conclude based on a meta-study of many experiments in the literature as well as additional own experiments that collusion occurs sometimes in duopolies. The stage game Nash equilibrium seems a good predictor for tripolies. Moreover, collusion appears rarely in oligopolies with more than two firms. In our experiment we avoid this number effect (on purpose) largely because we focus on a Cournot tripoly instead of a duopoly.

We believe that a three-player game is a fairer comparison to a team-player game than a two-player game because also in terms of the complexity of strategic reasoning two-player games differ slightly from $n$-player games, for $n \geq 3$. In a two-player game, each player can reason at most about one other opponent. This is in contrast to $n$-player games, where each player may have to reason also about what one opponent reasons about yet another opponent. In our design, we want to avoid that just the difference in the complexity of strategic reasoning between two-player games and team-players games drives any experimental result.

Huck, Konrad, Müller and Normann (2007) find that merged firms behave significantly more aggressive than their competitors in experimental Cournot competition. This could be contrasted with Observations 3 and 4 in Section 3.2. If a team-firm is 
viewed as a "merged" firm, then we find no differences in average behavior of merged and non-merged firms. Huck, Konrad, Müller and Normann (2007) explain their result with the merger history and aspiration levels based on pre-merger profits. In their experiment, subjects experienced the merger during the experiment. In contrast, our team-firms do not have any merger experience. We conclude that while we see no difference between team-firms and individual firms, such differences may arise if subjects do indeed experience a "merger" into a team-firm during the experiment.

\section{A Translation of Instructions: Treatment SP}

\section{Welcome to the experiment!}

In this experiment you can earn money by making decisions. Your earnings will depend on your decisions as well as the decisions of the other participants. Please read the instructions carefully. All participants received the same instructions. From now on please do not talk to other participants anymore. For any questions please do not hesitate to contact us.

You will draw shortly a random number. With this number you will remain anonymous for us and other participants during the experiment. Please proceed to the cabin in the laboratory with the same number.

\section{Firms}

When arriving at your cabin, you will be matched automatically and randomly with other participants into a firm without knowing the other participants. In every firm there are 3 members (except you there are two other members in your firm). Each market consist of 3 firms (except your firm there are two other firms in your market). The experiment consists of 40 periods which are followed by a questionnaire. The matching of the participants in firms remains the same throughout the 40 periods. Moreover, there are always the same firms in a market. In each period each firm sells a quantity in the market. The costs to the firm are 1 Taler per quantity. The price per quantity depends on your firm's quantity as well as the quantities of the other two firms in your market. The higher the quantities in the market, the lower the price. The lowest possible price is nil. The price function is

$$
\begin{aligned}
& \text { price per } \\
& \text { quantity }
\end{aligned}=500-\left(\frac{1}{6} \times \begin{array}{c}
\text { total quantity of all } \\
\text { firms in the market }
\end{array}\right) \text { or } 0
$$

The profit per quantity is the profit of the firm per quantity. It is calculated as follows:

$$
\text { profit per quantity }=\begin{gathered}
\text { price per } \\
\text { quantity }
\end{gathered}-\begin{gathered}
\text { firm costs per } \\
\text { quantity }
\end{gathered}
$$

The profit of the firm per period is simply the profit per quantity multiplied with the quantity of the firm: 
profit of the firm $=$ profit per quantity $\times$ quantity of the firm

\section{Your decision}

In each period each participant has to take a decision about her effort spent in the firm. The effort can lie between 0 and 1500 (in steps of 0.1). The costs to each participant per effort is

$83 \frac{1}{6}$ Taler. The sum of all efforts over all participants within a firm is the quantity of the firm, which the firm sells in the market.

quantity of the firm $=$ sum of efforts of all members within the firm

Each member of a firm receives a share of the profit of the firm. This share is calculated as follows:

$$
\underset{\text { firm's profit }}{\text { fire on }}=\frac{\text { own effort }}{\text { sum of efforts of all members }} \times \text { firm's profit }
$$

The costs of effort is calculated from the costs per effort of $83 \frac{1}{6}$ Taler multiplied with the own effort.

$$
\begin{gathered}
\text { costs of } \\
\text { effort }
\end{gathered}=\text { costs per effort } \times \text { own effort }
$$

The payoff to a participant per period is calculated as follows:

$$
\text { payoff }=\text { share on the firm's profit }- \text { cost of effort }
$$

\section{Computer}

We use the computer for the input of the decisions, for trying out of decisions and for the calculation of payoffs. Latter is done automatically. At the beginning of each period you can see the following screen (top left in the corner you can find the number of the period):

(1) Values of the previous period

To your information you find the values of the previous period at the screen. They are nil in the first period.

\section{(2) Support for Calculations}

Second, there are two calculators for trying out possible decisions, which you can use. The input into the calculators does not influence your payoffs. The calculator left (2a) calculates the payoff $(\mathrm{g})$ if you put in your possible effort (e), your belief about the efforts of the other members in your firm (a) as well as your belief about the quantities of the other firms (A). After 


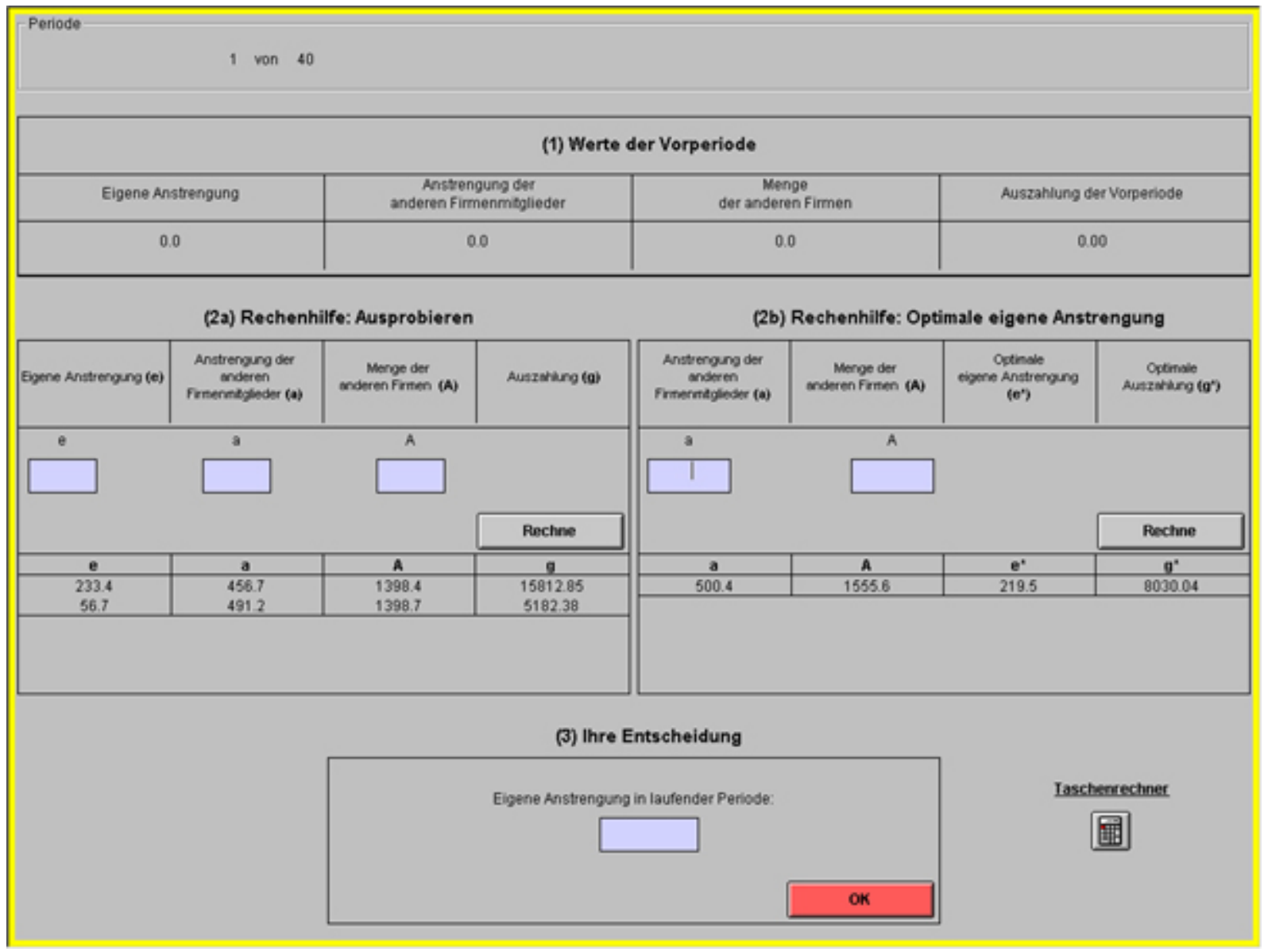

the input, the input data will be listed together with the calculated payoff under the calculator if you press the "calculate" button with the mouse. The effort of the other members in your firm (a) is calculated as follows:

$$
\begin{aligned}
& \text { effort of other } \\
& \text { members of the firm (a) }
\end{aligned}
$$

The quantity of the other firms (A) is

$$
\begin{array}{ll}
\underset{\text { quantity of other }}{\text { firms (A) }} & \text { sum of quantities of the other two firms } \\
& =\text { sum of efforts of all members of the other two firms }
\end{array}
$$

The calculator to the right side (2b) calculates your optimal own effort $\left(e^{*}\right)$ and your optimal payoff $\left(g^{*}\right)$ if you input your belief about the efforts of the other members of the your firm (a) as well as your belief about the quantities of the other firms (A). The optimal own effort $\left(e^{*}\right)$ is the effort which maximizes your payoff in this period if the other members of your firm and the other firms behave as input by you. Your calculations are listed under the calculator after you press the "calculate" button with the mouse. At the right side below the calcula- 
tor there is also a button. If you press this button a standard calculator appears on your screen.

(3) Your decision

In (3) you have to choose your effort level. In contrast to the calculators, this input will influence your payoff as outlined above. Only after you pressed "OK", your decision will be confirmed and the experiments proceeds with the next period. After 40 periods a questionnaire appears at the screen, which we kindly ask you to fill in.

\section{Your final payoff}

Since in this experiment there can be losses in a period, you will receive at the beginning an initial balance of 60000 Taler. For your final payoff we calculate the sum of your initial balance plus the sum of payoffs of all periods. This payoff in Taler will be exchanged into EURO using an exchange rate of 400 Taler $=1$ Cent. This will be paid to you immediately after the experiment.

\section{References}

[1] Bornstein, G. (2007). A classification of games by player type, mimeo., The Hebrew University of Jerusalem.

[2] Bornstein, G. and U. Gneezy, 2002, Price competition between teams, Experimental Economics, 5, 29-38.

[3] Bornstein, G., Kugler, T., Budescu, D., and R. Selten, 2007, Repeated price competition between individuals and between teams, Journal of Economic Behavior and Organization, forthcoming.

[4] Dolbear, F.T., Lave, L.B., Bowman, G., Lieberman, A., Prescott, E., Rueter, F., and R. Sherman, 1968, Collusion in oligopoly. An experiment on the effect of numbers and information, Quarterly Journal of Economics, 82, 240-259.

[5] Dufwenberg, M. and U. Gneezy (2000). Price competition and market concentration: An expermental study, International Journal of Industrial Organization, 18, 7-22.

[6] Fershtman, C. and K. L. Judd, 1987, Equilibrium incentives in oligopoly, American Economic Review, 77, 927-940.

[7] Fischbacher, U., 1999, z-Tree. Toolbox for readymade economic experiments, IEW Working Paper 21, University of Zurich.

[8] Fouraker, L. and S. Siegel, 1963, Bargaining behavior (McGraw-Hill, New York).

[9] Hart, O., 1995, Firms, contracts and financial structure (Claredon Press, Oxford).

[10] Huck, S., Konrad, K.A., Müller, W., and H.T. Normann, 2007, The merger paradox and why aspiration levels let it fail in the laboratory, Economic Journal, forthcoming. 
[11] Huck, S., Müller,W., and H.T. Normann, 2004, Strategic delegation in experimental markets, International Journal of Industrial Organization, 22, 561-574.

[12] Huck, S., Normann, H.-T., and J. Oechssler, 1999, Learning in Cournot oligopoly - An experiment, Economic Journal, 109, C80-C95.

[13] Huck, S., Normann, H.T., and J. Oechssler, 2004, Two are few and four are many: Number effects in experimental oligopolies, Journal of Economic Behavior and Organization, 53, 435-446.

[14] Lazear, E., 1995, Personnel economics (MIT Press, Cambridge, M.A.).

[15] Monderer, D. and L. Shapley, 1996, Potential games, Games and Economic Behavior, 14, 124-143.

[16] Nabantian, H. R., and A. Schotter, 1997, Productivity under group incentives: An experimental study, American Economic Review, 87, 314-341.

[17] Prendergast, C., 1999, The provision of incentives in firms, Journal of Economic Literature, $37,7-63$.

[18] Sauermann, H. and R. Selten, 1959, Ein Oligopolexperiment, Zeitschrift für die gesamte Staatswissenschaft, 115, 427-471.

[19] Siegel, S. and N. J. Castellan, 1988, Nonparametric statistics for the behavioral sciences (2nd edition, McGraw-Hill, New York).

[20] Vickers, J., 1985, Delegation and the theory of the firm, Economic Journal, 95, 138-147. 